\title{
Farklı azot dozlarının kişniş (Coriandrum sativum L.) yaş herba uçucu yağ bileşenleri üzerine etkisi
}

\author{
Effect of different nitrogen doses on coriander (Coriandrum sativum L.) fresh herba essential oil \\ components
}

\author{
Musa TÜRKMEN ${ }^{1 \mathscr{O}}$ (D), Ahmet MERT ${ }^{1}$ \\ ${ }^{1}$ Hatay Mustafa Kemal University, Faculty of Agriculture, Department of Field Crops, Antakya-Hatay, Turkey.
}

MAKALE BILGISI / ARTICLE INFO

\section{Makale tarihçesi / Article history:}

DOI: $10.37908 /$ mkutbd. 731874

Geliş tarihi /Received:04.05.2020

Kabul tarihi/Accepted:29.06.2020

\section{Keywords:}

Coriander, nitrogen, essential oil, Coriandrum sativum, fresh herba, GC-MS.

\footnotetext{
Corresponding author: Musa TÜRKMEN

$\triangle$ : turkmenmusa@hotmail.com
}

\author{
Ö ZET / A B STR A C T
}

Atıf / Citation: Türkmen M, Mert A (2020) Farklı azot dozlarının kişniş (Coriandrum sativum L.) yaş herba uçucu yağ bileşenleri üzerine etkisi. MKU. Tar. Bil. Derg. 25(3) : 309-315. DOI: 10.37908/mkutbd.731874

\section{GíRiş}

Kişniş (Coriandrum sativum L.), tek yıllık Apiaceae (Umbellifera) familyasına ait bir bitkidir. Akdeniz bölgelerine özgü olan kişniş şu anda birçok ülkede yetiştirilmektedir. Türkiye' de kişniş, 'aşotu', 'kuzbere' gibi isimlerle bilinen bir bitkidir (Baytop, 1994, Tonçer ve ark., 1998, Telci ve ark., 2006b). Kişniş yeşil aksamı bazı ülkelerde "Çin maydanozu" adıyla bilinip kullanılmakta ise de, bitkinin asıl kullanılan kısımları tohumlarıdır (Kan, 2007). Kişnişin meyve büyüklüğüne göre sınıflandırılan, Coriandrum sativum L. var. vulgare Alef. ve Coriandrum sativum L. var. microcarpum olmak üzere iki varyetesi vardır. Meyve çapı 3-5 mm çapında ve uçucu yağ verimleri \% 0.1-0.35 arasında olan Coriandrum sativum L. var. vulgare Alef. olarak isimlendirilirken, diğer çeşit ise daha küçük meyvelere sahip (1.5-3 mm çapında) ve uçucu yağ verimleri \% 0.8 -\% 1.8 arasında değişiklik gösteren Coriandrum sativum L. var. microcarpum DC. varyetesidir (Mandal ve Mandal, 2015, Diederichsen, 1996). Kişnişin meyveler ve yeşil herbaları da dahil olmak üzere farklı kısımları tıbbi amaçlarla halk hekimliğinde kullanılmaktadır (Ghamarnia ve Daichin, 2013). Kişniş meyvelerinin baharat olarak kullanımının yanında 
meyvelerinden elde edilen uçucu yağlar, içki sanayisinde de kullanılabilmektedir. Ayrıca antimikrobiyal etkinliğe sahip olmaları (Burst, 2004, Matasyoh ve ark., 2009) sebebiyle gıda ve parfümeri sanayinde kullanımı hızla artmaktadır (Beyzi ve Gürbüz 2010, Ceylan 1987, Doğan ve Akgül, 1984). Kişniş bitkisinin yaprakları ağrı kesici, sakinleştirici ve kuvvet verici; meyveleri ateş düşürücü, iştah açıcı, gaz giderici, laksatif ve idrar söktürücü özelliğe sahiptir (Baytop, 1984). Kişnişin yeşil herbalarının sebze ve baharat olarak kullanımının yanı sıra (Demir, 2006), kurutularak ve salamurası yapılarak da değerlendirilebilmektedir (Bahadırlı ve ark., 2016). Kişnişin yeşil yaprakları, chutney, sos hazırlama, lezzet körileri ve çorbalarda taze bitki olarak tüketilmektedir (Asgarpanah ve Kazemivash, 2012). Kişniş üzerine yapılan çalışmalarda bitkinin yaprakları, meyveleri kadar ayrıntılı incelenmemiştir (Ulutaş-Deniz ve ark., 2018.). Uçucu yağ bitkilerin çeşitli kısımlarından ekstrakte edilebilir: yapraklar, çiçekler, gövde, tohumlar, kökler ve ağaç kabuğu dahil. Bununla birlikte, uçucu yağın bileşimi, aynı bitkinin farklı kısımları arasında değişebilir; örneğin kişniş tohumundan elde edilen uçucu yağ, kişniş çiçeğinin uçucu yağından ve kişnişten (olgunlaşmamış yapraklar) farklıdır (Mandal ve Mandal, 2015). Daha önce yapılan çalışmalarda kişnişte farklı azot dozlarının tohum verimi ve agronomik özellikler üzerine etkinliği araştırılmış olup (Telci ve Avcl, 2006a, Erdoğdu ve Esendal, 2018); farklı azot dozlarının kişnişin taze herba uçucu yağ bileşenleri üzerine etkisi ile ilgili herhangi bir çalışmaya rastlanılamamıştır.

Bu çalışmada, farklı azot dozlarının $\left(0,3,6,9,12 \mathrm{~kg} \mathrm{da}^{-1}\right)$, Hatay koşullarında yetiştirilen kişniş (Coriandrum sativum var. vulgare) popülasyonlarında taze herba uçucu yağ bileşenleri üzerine etkinliğinin belirlenmesi amaçlanmıştır.

Çizelge 1. Deneme alanının özellikleri

Table 1. Features of the trial area

\begin{tabular}{|c|c|c|c|c|c|}
\hline Saturasyon (\%) & Toplam Tuz (\%) & $\mathrm{pH}$ & Kireç (\%) & Fosfor $\left(\mathrm{kg} \mathrm{da}^{-1}\right)$ & Organik Madde (\%) \\
\hline 59 & 0.0078 & 7.12 & 6.45 & 7.41 & 1.93 \\
\hline Killi-tınlı & Tuzsuz & Hafif alkali & Orta & Orta & $A z$ \\
\hline
\end{tabular}

\section{Bitki uçucu yağların elde edilmesi}

Çalışmamızda kullanılan uçucu yağlar kişniş (aşotu) taze herbalarından ( $500 \mathrm{~g}$ ) ve su distilasyonu yöntemiyle elde edilmiştir. Bitkilerin uçucu yağları clevenger ile 3 saatlik destilasyon ile elde edilmiştir. Destilasyon sonucu elde edilen uçucu yağlar analizleri yapılıncaya kadar $+4{ }^{\circ} \mathrm{C}^{\prime}$ de koyu renkli cam şişelerde saklanmıştır.

\section{MATERYAL ve YÖNTEM}

Deneme Hatay Mustafa Kemal Üniversitesi, Ziraat Fakültesi araştırma ve uygulama alanında yürütülmüştür. Bu çalışmada Coriandrum sativum var. vulgare (büyük tohumlu) kişniş varyetesine 4 farklı azot dozu $N_{0}, N_{1}, N_{2}, N_{3}, N_{4}\left(N_{0}=0, N_{1}=3, N_{2}=6, N_{3}=9, N_{4}=12 \mathrm{~kg}\right.$ $\mathrm{da}^{-1}$ ) uygulanmıştır. Azotun yarısı ekimden önce ve diğer yarısı ise bitkiler $10 \mathrm{~cm}$ boyuna ulaştığında uygulanmıştır. Deneme bölünmüş parseller deneme desenine göre üç tekrarlamalı olarak kurulmuştur. Bu denemede kişniş varyetesi ana parselleri azot dozları ise alt parselleri oluşturmaktadır. Parseller $2 \mathrm{~m}$ uzunluğunda 6 sıra ve sıra arası $30 \mathrm{~cm}$ olarak düzenlenmiştir. Denemede tohumlar 29 Ocak 2020 tarihinde $2.5 \mathrm{~kg} \mathrm{da}^{-1}$ hesaplanarak tarlaya ekimi gerçekleştirilmiştir. Ekimden önce tabana $6 \mathrm{~kg} \mathrm{da}^{-1}$ gelecek şekilde fosfor gübresi uygulanmıştır. Deneme süresince yabancı otlarla mücadele mekanik yollarla yapılmıştır. Deneme alanında sulama yapılmamıştır. Bitkilerde hasat ise 13 Nisan 2020 tarihinde çiçeklenme öncesi dönemde gerçekleştirilmiştir.

\section{Deneme yerinin toprak özellikleri}

Deneme alanına ait toprak özellikleri, deneme alanından 0-30 cm derinlik ve farklı yerlerinden alınan toprak örneğinin Hatay Mustafa Kemal Üniversitesi, Teknoloji ve Araştırma Geliştirme Uygulama ve Araştırma Merkezi'nde analizi yapılarak tespit edilmiştir (Yılmaz ve ark. 2018). Denemenin yürütüldüğü topraklara ait bazı özellikler Çizelge 1 'de verilmiştir. Çizelge 1 'de görüldüğü gibi, deneme alanı toprağının killi-tınlı özellikte, hafif alkali, orta derecede kireç ve fosfor içeren, organik maddece zayıf topraklar olduğu tespit edilmiştir.

\section{Uçucu yağ bileşenlerinin belirlenmesi}

Kişniş taze herba uçucu yağ bileşenlerinin belirlenmesi gaz-kromatogafik yöntem ile saptanmıştır. Uçucu yağ bileşenlerinin belirlenmesi Thermo Scientific ISQ Single Quadrupole model Gaz Kromatogafi cihazı ile aşağıdaki şartlar altında gerçekleştirilmiştir. TR-FAME MS model, $\% 5$ Phenyl Polysilphenylene-siloxane, $0.25 \mathrm{~mm}$ iç çap $x$ $60 \mathrm{~m}$ uzunlukla, $0.25 \mu \mathrm{m}$ film kalınlığına sahip kolon kullanılmıştır. Taşıyıcı gaz olarak $1 \mathrm{~mL} \mathrm{dk}^{-1}$ akış hızında helyum (\% 99.9) kullanılmıştır. İyonizasyon 22 enerjisi 70 
eV, kütle aralığı m/z 1,2-1200 amu olarak ayarlanmıştır. Veri toplamada tarama modu (Scan Mode) kullanılmıştır. MS transfer line sıcaklığı $250^{\circ} \mathrm{C}$, MS iyonizasyon sıcaklığı $220{ }^{\circ} \mathrm{C}$, Enjeksiyon port sıcaklığı $220^{\circ} \mathrm{C}$, kolon sıcaklığı başlangıçta $50^{\circ} \mathrm{C}$ olup $3{ }^{\circ} \mathrm{C} \mathrm{dk}^{-1}$ ISı artış oranı ile $220^{\circ} \mathrm{C}^{\prime}$ ye kadar yükseltilmiştir. Her bileşiğin yapısı Xcalibur progamı ile kütle spektrumları kullanılarak (Wiley 9) tanımlanmıştır.

\section{BULGULAR ve TARTIŞMA}

$\mathrm{Bu}$ çalışmada, Hatay koşullarında yetiştirilen kişniş bitkisinde, farklı azot dozlarının taze herba uçucu yağların bileşenleri üzerine etkinliği incelenmiştir
(Çizelge 2). Yapılan Gc-Ms analizi sonucunda, ana bileşenlerin, kontrol grubu ( $0 \mathrm{~kg} \mathrm{da}^{-1}$ ) ve bütün gübre dozları için (3, 6, 9, $\left.12 \mathrm{~kg} \mathrm{da}^{-1}\right)$; 2-Decenal, 2-Dodecanal, Decanal, Cyclodecanol, 13-Tetradecanal, Dodecanal, 1Decanol, Undecanol, 2-Tridecenal, olduğu tespit edilmiştir. Artan azot dozu uygulamalarının uçucu yağ bileşenleri üzerine etkisi ayrı ayrı incelendiğinde, ana bileşenlerin oranlarının farklııklar gösterdiği açıkça görülmektedir. Gübre dozlarının artması ile birlikte tespit edilen ana bileşenlerin oranlarının bir kısmında artmalar gözlemlenirken, bazı bileşenlerin oranlarında ise azalmalar gözlemlenmiştir. Bileşenlerin bir kısmında ise büyük bir değişim gözlemlenmemiştir.

Çizelge 2. Farklı azot dozu uygulamalarının kişniş taze herba uçucu yağlarının bileşenleri üzerine etkinliği

Table 2. Effectiveness of different nitrogen doses applications on the components of coriander fresh herba essential oils

\begin{tabular}{|c|c|c|c|c|c|c|c|c|c|}
\hline RT & Bileşenler & SI & RSI & Cas & $\begin{array}{l}\mathrm{N}_{0} \\
(\%)\end{array}$ & $\begin{array}{l}\mathrm{N}_{1} \\
(\%)\end{array}$ & $\begin{array}{l}\mathrm{N}_{2} \\
(\%)\end{array}$ & $\begin{array}{l}\mathrm{N}_{3} \\
(\%)\end{array}$ & $\begin{array}{c}\mathrm{N}_{4} \\
(\%)\end{array}$ \\
\hline 6.14 & 1-Octene.3.4-dimethyl & 864 & 897 & $56728-11-1$ & 0.13 & 0.08 & 0.11 & 0.10 & 0.17 \\
\hline 12.05 & Eucalyptol & 799 & 804 & $470-82-6$ & 0.18 & 0.07 & 0.12 & 0.28 & 0.24 \\
\hline 15.71 & Octanal & 964 & 987 & $124-13-0$ & 0.18 & 0.41 & 0.56 & 0.56 & 0.61 \\
\hline 19.25 & Nonanal & 958 & 971 & $124-19-6$ & 0.60 & 0.48 & 0.47 & 0.74 & 0.78 \\
\hline 22.77 & Decanal & 995 & 996 & $112-31-2$ & 15.35 & 15.31 & 15.95 & 15.08 & 15.11 \\
\hline 24.58 & 1-Nonanol & 951 & 967 & $143-08-8$ & 0.24 & 0.17 & 0.16 & 0.30 & 0.32 \\
\hline 26.24 & Undecanal & 982 & 985 & $112-44-7$ & 3.15 & 3.70 & 3.72 & 4.44 & 4.31 \\
\hline 27.8 & 1-Decanol & 987 & 988 & $112-30-1$ & 4.32 & 6.62 & 6.96 & 10.47 & 11.38 \\
\hline 28.69 & 2-Decenal & 980 & 983 & $3913-81-3$ & 31.85 & 23.03 & 24.56 & 14.80 & 14.29 \\
\hline 29.05 & Cyclodecanol & 963 & 963 & $1502-05-2$ & 6.03 & 8.83 & 8.97 & 10.67 & 12.19 \\
\hline 29.55 & Dodecanal & 973 & 987 & $112-54-9$ & 4.65 & 4.87 & 4.50 & 4.58 & 4.82 \\
\hline 31.0 & 1-Undecanol & 975 & 982 & $112-42-5$ & 0.87 & 0.77 & 0.77 & 1.18 & 1.13 \\
\hline 32.05 & 2-Tridecenal & 952 & 969 & $1337-83-3$ & 3.65 & 5.04 & 5.17 & 4.56 & 4.08 \\
\hline 32.2 & trans-2-Dodecen-1-ol & 978 & 983 & $69064-37-5$ & 0.67 & 0.36 & 1.01 & 1.47 & 1.85 \\
\hline 34.01 & Cyclododecane & 980 & 982 & $294-62-2$ & 0.33 & 0.25 & 0.21 & 0.24 & 0.35 \\
\hline 35.21 & 2-Dodecenal & 975 & 977 & $4826-62-4$ & 15.74 & 15.66 & 13.39 & 13.37 & 11.41 \\
\hline 35.71 & Tetradecanal & 967 & 972 & $124-25-4$ & 0.81 & 0.65 & 0.71 & 0.70 & 0.62 \\
\hline 38.23 & 7-Tetradecenal & 929 & 936 & 65128-96-3 & 0.50 & 0.59 & 0.63 & 0.50 & 0.34 \\
\hline 41.06 & 13-Tetradecenal & 947 & 948 & 85896-31-7 & 4.96 & 7.00 & 6.86 & 4.74 & 2.96 \\
\hline 46.87 & Oleic Acid & 891 & 894 & $112-80-1$ & 0.24 & 0.08 & 0.05 & 0.06 & 1.45 \\
\hline \multicolumn{2}{|c|}{ Toplam } & & & & 94.45 & 93.97 & 94.87 & 88.84 & 88.41 \\
\hline
\end{tabular}

*Çizelgede oranları \%0.05 ve altı olan bileşenler dikkate alınmamıştır.

CAS: Kimyasal maddenin kimyasal kuramlar servisi tarafından verilen numarasıdır.

SI: Kütüphane spektrumu için eşleştirme faktörü

RSI: Kütüphane spektrumu için ters eşleştirme faktörü

Gübre dozunun artması ile Cyclodecanol, 1-Decanol ve Undecanal bileşenlerin oranlarının kontrole kıyasla artış gösterdiği tespit edilmiştir (Şekil 1). Bu bileşenlerin oranları incelendiğinde Cyclodecanol kontrol parsellerinde $\% 6.03$ olarak tespit edilirken $\mathrm{N}_{1}$ uygulamasında \%8.83, $\mathrm{N}_{2}$ gübre uygulamasında $\% 8.97$ olarak tespit edilmiştir. $\mathrm{Bu}$ oranın $\mathrm{N}_{3}$ ve $\mathrm{N}_{4}$ uygulamalarında sırasıyla \%10.67 ve \%12.19 oranlarına yükseldiği belirlenmiştir. 1-Decanol oranı gübre uygulamaları yapılmayan kontrol parsellerinde \%4.32 olarak belirlenirken $N_{1}, N_{2}, N_{3}$ ve $N_{4}$ uygulamalarında sırasıyla $\% 6.62, \% 6.96, \% 10.47$ ve $\% 11.38$ olarak tespit edilmiştir. Undecanal açısından incelendiğinde ise; oranlar sırasıyla kontrol parseli ve $N_{1}, N_{2}, N_{3}$ ve $N_{4}$ 
uygulamalarında \%3.15, \%3.70, \%3.72, \%4.44 ve \%4.31

olarak tespit edilmiştir.

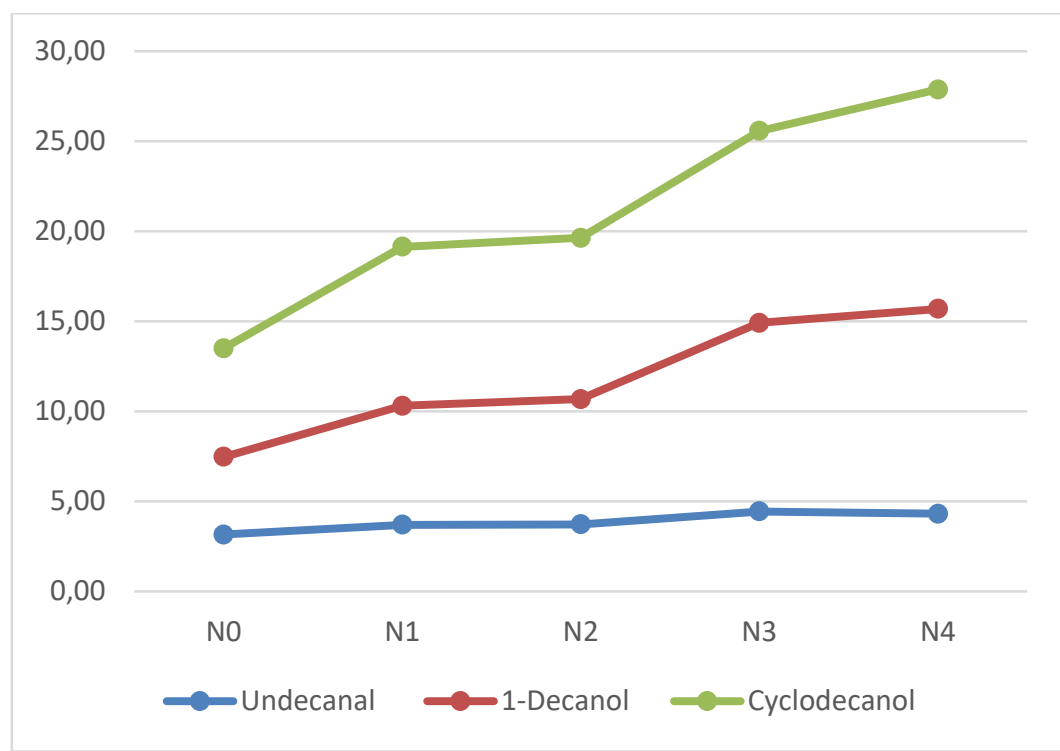

Şekil 1. Farklı azot dozu ile birlikte oranları artan ana bileşenler

Figure 1. The main components that increase in proportion with different doses of nitrogen

Artan gübre dozu ile oranları azalan bileşenler incelendiğinde (Şekil 2); 2-Decenal bileşeninin oranı uygulama yapılmayan (kontrol) parsellerimizde \%31.85 olarak tespit edilmiştir. Gübre uygulanan parsellerde artan gübre dozları ile birlikte bu oranın $\mathrm{N}_{1}, \mathrm{~N}_{2}, \mathrm{~N}_{3}$ ve $\mathrm{N}_{4}$ gübre uygulamaları için sırasıyla; \%23.03, \%24.56,
\%14.80 ve \%14.29 olarak azalan eğilimde bir değişim gösterdiği belirlenmiştir. 2-Dodecenal bileşeninin kontrol parsellerinde \%15.74 olduğu tespit edilirken bu oranın artan gübre dozu uygulamaları ile azaldığı görülmektedir ( $\mathrm{N}_{1}-\% 15.66, \mathrm{~N}_{2}-\% 13.39, \mathrm{~N}_{3}-\% 13.37$ ve $\mathrm{N}_{4}$ \%11.41).

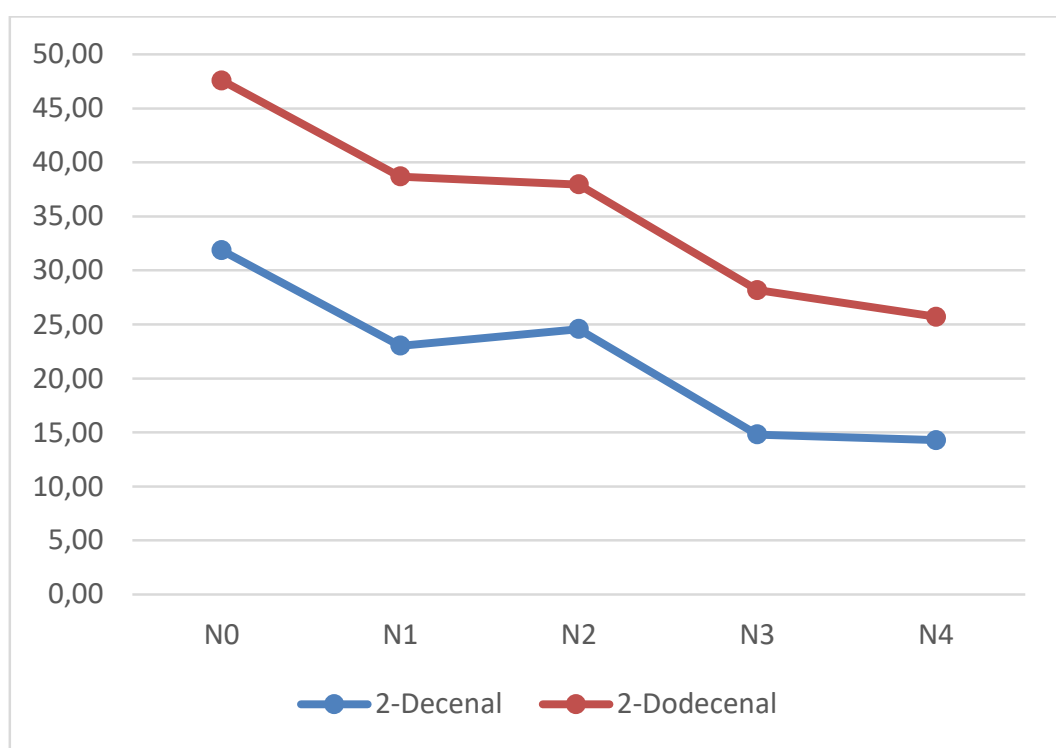

Şekil 2. Farklı azot dozu ile birlikte oranları azalan ana bileşenler

Figure 2. The main components of which rates decrease with different nitrogen doses

Tespit edilen ana bileşenlerden, Decanal ve Dodecanal oranlarına bakıldığında bu bileşenlerin oranlarının kontrol grubu ile kıyaslandığında çok büyük farklılık göstermediği belirlenmiştir (Şekil 3). 


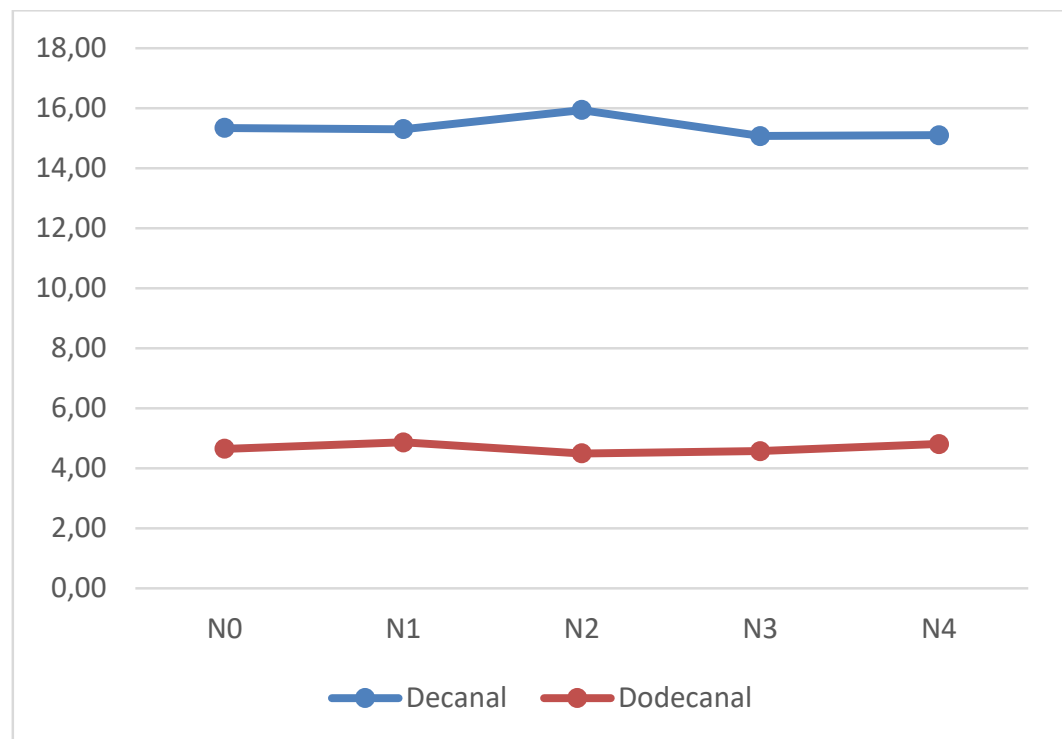

Şekil 3. Farklı azot dozu ile birlikte oranları çok fazla değişim göstermeyen ana bileşenler

Figure 3. The main components that do not change much with different nitrogen doses

Çizelge 2'de görüldüğü gibi, 2-Tridecenal ve 13Tetradecenal bileşenlerinin oranlarının $\mathrm{N}_{1}$ ve $\mathrm{N}_{2}$ uygulamalarında kontrole kıyasla arttığı (\%5.04 ve \%5.17 sırasıyla) ve daha sonra artan gübre dozları ile tekrardan azaldığı ( $\mathrm{N}_{3}-\% 4.56$ ve $\mathrm{N}_{4}-\% 4.08$ ) tespit edilmiştir (Şekil 4).

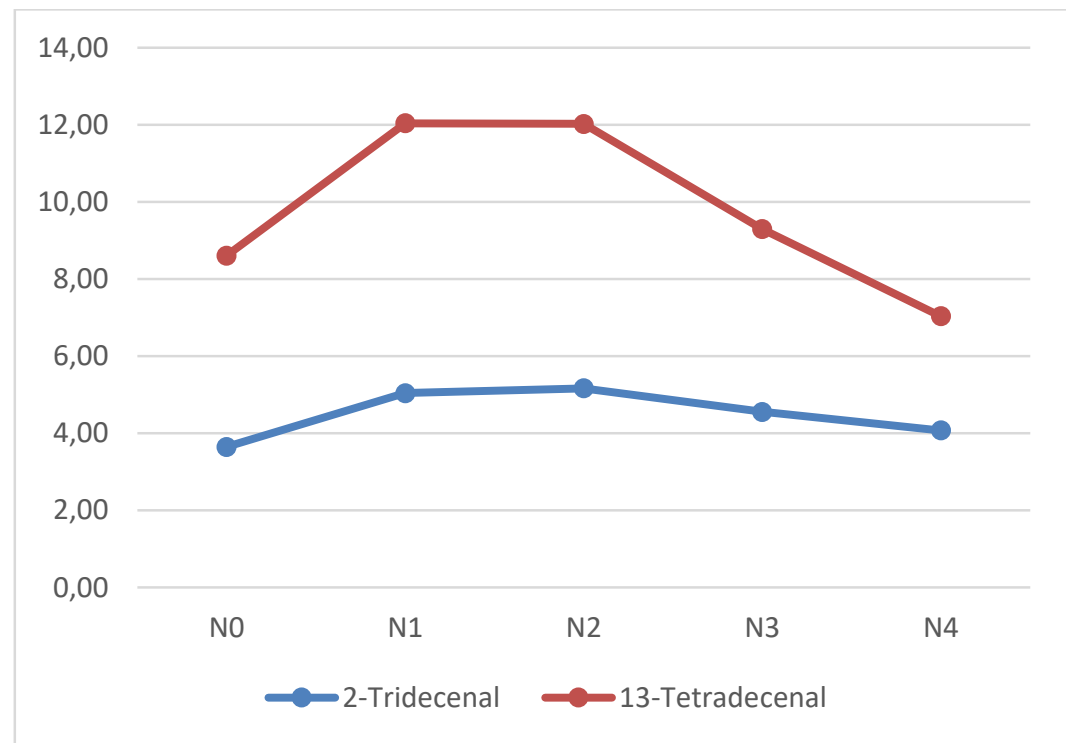

Şekil 4. Farklı azot dozu ile birlikte oranları önce artan daha sonra azalan ana bileşenler Figure 4. The main components that increase and then decrease with the different nitrogen doses

Kişniş herba uçucu yağ bileşenleri üzerine yapılan çeşitli çalışmalarda da ana bileşenler yapılan bu çalışma ile benzer sonuçlar göstermektedir (Bahadırlı ve ark., 2016, Freires ve ark., 2014, Nurzyńska-Wierdak R, 2013, Chung ve ark., 2012, Matasyoh ve ark., 2009, Bhuiyan ve ark., 2009,). Kişnişte farklı azot dozlarının etkinliği üzerine daha önce yapılan çalışmalarda genel olarak azot dozlarının kişnişte tohum verimi ve agronomik özellikler üzerine etkinliği araştırılmıştır (Erdoğdu ve Esendal, 2018, Telci ve Avcl, 2006).
Farklı azot dozlarının $\left(0,3,6,9,12 \mathrm{~kg} \mathrm{da}^{-1}\right)$, Hatay koşullarında yetiştirilen kişniş (Coriandrum sativum var. vulgare) 'de taze herba uçucu yağ bileşenleri üzerine etkinliğinin belirlenmesi amacıyla yapılan bu çalışmada, gübre dozlarının artması ile Undecanal, 1-Decanol ve Cyclodecanol oranlarının arttığı tespit edilirken, 2Decenal ve 2-Dodecenal oranlarının ise azaldığı belirlenmiş̧ir. Azot dozunun değişimi ile artış ya da azalış gösteren bileşenlerin yanı sıra Decanal ve Dodecanal oranlarında ise çok fazla bir değişim gözlenmemiştir. Bu 
çalışma ile kişniş taze herba uçucu yağındaki etken maddelerin, kullanım amacına göre uygun azot dozlarının belirlenmesi sağlanmıştır. Bu yönüyle kişniş taze herba uçucu yağı bileşenlerinin antimikrobiyal çalışmalarda kullanılabilirliği, ayrıca farklı bitkilerin uçucu yağ bileşenleri üzerine azot uygulamalarının etkileri ileriki çalışmalarla da desteklenebileceği düşünülmektedir.

\section{ÖZET}

Amaç: Bu çalışmada, farklı azot dozlarının (0, 3, 6, 9, 12 $\left.\mathrm{kg} \mathrm{da}{ }^{-1}\right)$, Hatay koşullarında yetiştirilen kişniş (Coriandrum sativum var. vulgare) popülasyonunda taze herba uçucu yağ bileşenleri üzerine etkinliği araştırılmıştır.

Yöntem ve Bulgular: Kişniş tohumlarının (29 Ocak 2020) tarlaya ekimi gerçekleştirilmiştir. Azot dozlarının yarısı ekimle birlikte, diğer yarısı ise bitkiler 5-10 cm boylandığında uygulanmıştır. 13 Nisan 2020 tarihinde bitkiler hasat edilmiştir. Taze herba örnekleri 3 saat süre ile Clevenger tipi aparat kullanılarak su buharı distilasyon ile uçucu yağları elde edilmiş ve elde edilen uçucu yağ bileşenlerine GC-MS ile bakılmıştır. Sonuçlara göre ana bileşenler; kontrol parseli ve bütün gübre dozları için; 2Decenal, 2-Dodecanal, Decanal, Cyclodecanol, 13Tetradecanal, Dodecanal, 1-Decanol, Undecanol, 2Tridecenal, olarak tespit edilmiştir.

Genel Yorum: Gübre dozlarının artması ile birlikte tespit edilen ana bileşenlerin oranlarının bazılarında artmalar, bazılarında azalmalar gözlemlenirken bir kısmında ise büyük bir değişim gözlemlenmemiştir.

Çalışmanın Önemi ve Etkisi: Bu çalışma ile kişniş taze herba uçucu yağındaki etken maddeleri oluşturan bileşenlerin farklı azot dozuna tepkisi belirlenerek en uygun azot dozunun belirlenmesi sağlanmıştır. Bu yönüyle kişniş taze herba uçucu yağı bileşenlerinin antimikrobiyal çalışmalarda kullanılabilirliği, ayrıca farklı bitkilerin uçucu yağ bileşenleri üzerine azot uygulamalarının etkileri konularında yapılacak çalışmalarla da desteklenebileceği düşünülmektedir.

Anahtar Kelimeler: Kişniş, azot, uçucu yağ, Coriandrum sativum, taze herba, GC-MS.

\section{ÇIKAR ÇATIŞMA BEYANI}

Yazar(lar) çalışma konusunda çıkar çatışmasının olmadığını beyan eder.

\section{ARAŞTIRMACILARIN KATKI ORANI BEYANI}

Yazarlar çalışmaya eşit oranda katkı sağlamış olduklarını beyan eder.

\section{KAYNAKLAR}

Asgarpanah J, Kazemivash N (2012) Phytochemistry, pharmacology and medicinal properties of Coriandrum sativum L. African Journal of Pharmacy and Pharmacology Vol. 6(31): 2340-2345.

Bahadırlı NP, Türkmen M, Mert A (2016) Hatay koşullarında yetiştirilen aşotu (Coriandrum sativum L.) bitkisinin yaş herba ve tohum uçucu yağ oranlarının ve içeriklerinin belirlenmesi. Biyoloji Bilimleri Araştırma Dergisi, 9 (2): 20-22.

Baytop T (1984) Türkiye' de Bitkiler İle Tedavi. İstanbul Üniv. Yay. No;3255, Ecz. Fak. Yay. No: 40, İstanbul.

Baytop T (1994) Türkçe Bitki Adları Sözlüğü, Türk Dil Kurumu Yayınları No: 578.

Beyzi E, Gürbüz B (2010) Ülkemizde Kişniş (Coriandrum sativum L.) Üretimi ve Bitkinin Genel Özellikleri. Ziraat Mühendisliği, Sayı: 354, 24-27.

Bhuiyan MNI, Begum J, Sultana M (2009) Chemical composition of leaf and seed essential oil of Coriandrum sativum L. from Bangladesh. Bangladesh J Pharmacol. 4: 150-153.

Burst S (2004) Essential oils: Their antibacterial properties and potential application in foods a review. International Journal of Food Microbiology, 94, 223-253.

Ceylan A (1987) Tıbbi Bitkiler II (Uçucu Yağ İçerenler). Ege Üniversitesi, Ziraat Fakültesi Yayınları, No: 481, İzmir.

Chung $M$, Ateeque A, Sun-Jin K, Poornanand MN, Praveen N (2012) Composition of the essential oil constituents from leaves and stems of Korean Coriandrum sativum and their immunotoxicity activity on the Aedes aegypti L.. Immunopharmacology and Immunotoxicology, 34:1, 152-156.

Demir H (2006) Asotu (Coriandrum sativum) yapraklarından katalaz enziminin saflaştırılması ve bazı kinetik özelliklerinin arastırılması. Türkiye 9 . Gıda Kongresi; 24-26 Mayıs 2006 Bolu, sayfa 315-318.

Diederichsen A (1996) Promoting the conservation and use of underutilized and neglected crops. Coriander, Institute of Plant Genetics and Crop Plant Research. Gatersleben/International Plant. Genetic Resources Inst. N: pp 83.

Doğan A, Akgül A (1984) Kişniş üretimi, bileşimi ve kullanımı Doğa Türk Tarım ve Ormancılık Dergisi, 11 (2), pp. 326-333.

Erdoğdu Y, Esendal E (2018) The effects of nitrogen doses on the seed yield and some agronomic characteristics of Coriander cultivars. Journal of Tekirdag Agricultural Faculty., 15 (01), 95-101. 
Freires IDA, Murata RM, Furletti VF, Sartoratto A, Alencar SMD, Figueira GM, Rodrigues O, Duarte MC, PLet R (2014) Coriandrum sativum L. (Coriander) essential oil: antifungal activity and mode of action on Candida spp., and molecular targets affected in human wholegenome expression. PLoS One 2014; 9: e99086. (9);6., pp:1-13.

Ghamarnia H, Daichin S (2013) Effect of different water stress regimes on different Coriander (Coriandrum sativum L.) Parameters in a semi-arid climate. International Journal of Agronomy and Plant Production. Vol., 4 (4), 822-832.

Kan Y (2007) Konya ekolojik koşullarında yetiştirilen kişnişte uygulanan organik ve inorganik gübrelerin verim ve uçucu yağ oranı üzerine etkileri. Selçuk Üniversitesi, Ziraat Fakültesi Dergisi, 21 (42): 36-42.

Mandal S, Mandal M (2015) Coriander (Coriandrum sativum L.) essential oil: Chemistry and biological activity. Asian Pac Trop Biomed.;5(6):421-428.

Matasyoh JC, Maiyo ZC, Ngure RM, Chepkorir R (2009) Chemical composition and antimicrobial activity of essential oil of Coriandrum sativum. Food Chem 113: 526-529.

Nurzyńska-Wierdak R (2013) Essential oil compositiono of the coriander (Coriandrum sativum L.) herb depending on the development stage. Acta Agrobotanica Vol. 66 (1): 53-60.
Telci i, Avcı B (2006a) Changes in yields, essential oil and linalool contents of Coriandrum sativum varieties (var. vulgare Alef. and var. microcarpum DC.) harvested at different development stages. Europ.J.Hort.Sci., 71 (6). S. 267-271.

Telci I, Toncer OG, Sahbaz N (2006b) Yield, essential oil content and composition of Coriandrum sativum varieties (var. vulgare Alef and var. microcarpum DC.) grown in two different locations. J. Essent. Oil Res. 18: 189-193.

Tonçer Ö, Tansı S, Kızıl S (1998) Time on essential oil of Coriander in Gap Region. Anadolu, J. of AARI, 8 (2):101-105.

Ulutaş-Deniz E, Yeğenoğlu S, Sözen-Şahne B, GençlerÖzkan AM (2018) Kişniş (Coriandrum sativum L.) üzerine bir derleme. Marmara Pharm J.; 22 (1): 15-28.

Yılmaz Ş, Hür N, Ertekin I (2018) Seçilmiş Bazı Köpekdişi Ayrığı (Cynodon dactylon(L.) Pers. var. dactylon] hatlarında ot verimi ve kalitesinin belirlenmesi. MKÜ Ziraat Fakültesi Dergisi, 23(2):232-241. 